\title{
Dados diacrónicos da estrutura durativa em português e em galego
}

\author{
Paulo Osório \\ Universidade da Beira Interior (Portugal) \\ pjtrso@ubi.pt \\ Ignacio Vázquez Diéguez \\ Universidade da Beira Interior (Portugal) \\ jivd@ubi.pt
}

Recibido o 19/03/2018

Aceptado o 10/07/2018

\section{Diachronic evidence for durative constructions in Portuguese and Galician}

\section{Resumo}

O presente estudo tem como objetivo primordial refletir e problematizar o funcionamento sintático e semântico das atuais construções durativas construídas, sob o ponto de vista sintático, com gerúndio vs. infinitivo gerundivo em formas ditas perifrásticas. A existência destas duas estruturas, com a mesma semântica, obriga a tentar saber por que existe essa duplicidade: socorrer-nos-emos, para o efeito, de dados diacrónicos. Sendo duas perífrases com uma semântica determinada (ideia de desenvolvimento da ação), ir-se-á procurar a estrutura latina que indicava o mesmo significado, isto é, igualmente uma perífrase, mas com constituintes diferentes. Estudar-se-á a substituição da perífrase latina pelas correspondentes portuguesas e galegas, tentando demonstrar um conjunto de mudanças que colaboram para uma explicação da criação da variante nova na superfície frásica. Por outro lado, atendendo aos constituintes referidos [v. auxiliar + (conector) + v. principal], far-se-á uma comparação entre o latim e o português e o galego (o verbo auxiliar muda do latim - esse - para o português e o galego - estar - assim como o verbo principal que detém a significação, no latim, um particípio de presente, e no português e galego o gerúndio ou o infinitivo gerundivo). Deste modo, a alteração dos constituintes exige, naturalmente, um estudo das formas latinas. Terá especial relevo o gerúndio, com funções no latim muito diferentes das que possui hoje nas línguas românicas e semeIhantes ao inglês, língua com a qual se comparará (para uma melhor compreensão da sua pretérita função). Ampliar-se-á a comparação a outras línguas românicas para examinar as diferentes ou parecidas soluções. Com todos os dados coligidos, tentar-se-á justificar a existência das duas estruturas sintáticas com semântica sinonímica e, consequentemente, a cronologia dos factos: de acordo com os registos escritos (desde o século XIII até à atualidade), procurar-se-á observar qual é a mais antiga e qual aparece posteriormente, bem como a frequência de uso no português europeu (PE), no português do Brasil (PB) e no galego, de cada uma delas. Para o enquadramento teórico, utilizaremos os princípios defendidos por Mattos e Silva (1989; 2008, vols. I e II) e, metodologicamente, para a recolha dos dados, utilizaremos os corpora on-line disponibilizados por algumas equipas de investigação.

\section{Abstract} the syntactic and semantic functioning of periphrastic present durative tenses the syntax of which contains either a gerund or an infinitive. The coexistence of both with a similar semantic value raises the question why there are two constructions, which this paper attempts to use diachronic data to answer. Given the existence of two periphrases with the same meaning, namely the idea of action in progress, we will ask how this was expressed in Latin using a different periphrastic construction. The paper traces the process of replacement of the Latin construction by those found in Portuguese and Galician, identifying a series of changes which help to explain how the new construction emerged. Given that the constituents of these constructions are auxiliary verb, (link) and main verb, this approach leads to a comparison between the Latin auxiliary verb esse and the Portuguese/Galician auxiliary estar, and also between the forms taken by the main verb, namely the Latin present participle versus the gerund or gerundial infinitive in Portuguese and Galician; hence the need to analyse the Latin forms. Special emphasis will be laid upon the gerund, which has very different functions in Latin from those which it has acquired in modern Romance languages; the latter are reminiscent of the English gerund, with which the Romance gerund will be compared to achieve a better understanding of its earlier functions. The comparison will be broadened to include other Romance languages so as to examine the similarities and differences in the solutions found. Having compiled all the data, an explanation will then be sought for the coexistence of two synonymous constructions which takes into account the chronology of changes on the basis of written records extending from the thirteenth century to the present day, in order to establish which construction is the older of the two and their frequency in European Portuguese (PE), Brazilian Portuguese (PB) and Galician. The theoretical framework of this study draws on principles defended by Mattos and Silva (1989, 2008, vols I and II); existing corpora are used as sources of data. 
Palabras chave

Gerúndio; infinitivo gerundivo; português; galego; diacronia

\section{Sumario}

1. Introdução. 2. Gerúndio e infinitivo gerundivo. 2.1. Aproximação diacrónica. 3. Estudo das formas finitas. 4. As estruturas em foco no português europeu, brasileiro e no galego. 5. Considerações finais.
Keywords

Gerund; gerundial infinitive; Portuguese; Galician; diachrony

\section{Contents}

1. Introduction. 2. Gerund and gerundial infinitive. 2.1. Diachronic approach. 3. Study of finite forms. 4. The constructions involved in European Portuguese, Brazilian Portuguese and Galician. 5. Final considerations.

\section{INTRODUÇÃO}

Alguns estudos parcelares sobre certos aspetos tratados nesta investigação têm sido publicados em revistas da especialidade, todavia seguindo outros enquadramentos teórico-metodológicos ao aqui referido e com dados, muitas vezes, de proveniência diferente dos nossos (cf., entre outros, Lobo, 2001; Lobo, 2008; Fiéis e Lobo, 2010). Neste artigo, seguiremos, assim, uma linha descritivista apoiada nas considerações levantadas em Mattos e Silva (fundamentalmente, 1989 e 2008, vols. I e II). Como refere Mattos e Silva (2008: 28-29, vol. I):

Partirei sempre de uma base de análise descritiva e, a depender do tópico sob análise e da bibliografia a ele referente e a mim disponível, utilizarei análises estruturalistas; análises com base na metodologia quantitativa, em geral de orientação laboviana; análises funcionalistas (...). Essa base teórico-metodológica não é, a meu ver, ecléctica, talvez heterodoxa.

Ao longo deste estudo, procurar-se-á analisar o funcionamento sintático e semântico do gerúndio vs. infinitivo gerundivo - nas chamadas perífrases durativas - desde o século XIII até à atualidade. A existência destas duas estruturas com a mesma semântica obriga a descrever as mudanças que se vão encaixando nos dados que desenham os caminhos estruturais da difusão e retração das variantes em mudança dessa duplicidade, a sua distribuição geográfica e o estádio de consolidação de cada uma delas: ajudar-nos-ão, assim, os dados diacrónicos.

Tratando-se de duas perífrases com uma semântica determinada (ideia de desenvolvimento da ação), tem de procurar-se a estrutura latina que indicava o mesmo significado e que era, igualmente, uma perífrase, mas com constituintes diferentes. Estudar-se-á, assim, a substituição da perífrase latina pelas correspondentes portuguesas e galegas, delineando o processo dessa mudança.

\section{Gerúndio e Infinitivo Gerundivo}

Existem, hoje, nas línguas portuguesa e galega duas estruturas sintáticas que se referem, na atualidade, ao mesmo conteúdo semântico: as perífrases durativas <estar + gerúndio > e <estar $+a+$ infinitivo $>$. É evidenciada em toda a bibliografia linguística que a primeira estrutura é atualmente mais utilizada no PB e galego e a segunda no PE. Por seu lado, o latim utilizava uma estrutura diferente: <particípio de presente + esse $>$.

O facto de o galaico-português, na sua fase inicial, ter substituído o paradigma latino implica, a nosso ver, um passo na evolução românica, tal como fizeram as restantes línguas procedentes do latim. No entanto, o facto de ter desenvolvido duas soluções, ainda hoje em uso, faz-nos refletir acerca da questão. Assim, descrever-se-á o percurso da substituição românica (que não afeta unicamente o português e o galego) e a dupla solução, parecendo-nos evidente que se deverá adotar uma metodologia que parta de uma pequena aproximação diacrónica (a partir do latim) de três formas verbais não finitas relacionadas neste estudo: o infinitivo, o gerúndio e o particípio do presente.

\subsection{Aproximação diacrónica}

Poder-se-á dizer que o infinitivo é um substantivo verbal indeclinável que, em latim, apenas podia assumir a função de sujeito ou também de complemento direto (OD) apenas numa estru- 
tura com verbos de perceção e de volição - volo beatus esse (quero ser feliz), origem das nossas perífrases atuais querer/preferir/saber... + infinitivo. O gerúndio era, igualmente, um substantivo verbal que substituía o infinitivo nos casos de que este carecia, mas não formava uma estrutura durativa. A estrutura durativa (semanticamente equivalente às atuais estar $+a+$ infinitivo / estar + gerúndio) era formada pelo verbo esse mais o particípio do presente (formas em -ns, $-n t i s$ ) $<$ part. pres. + esse $>$.

Antecedendo dados que se observarão, pormenorizadamente, mais adiante, Muñío (1995: 231) refere que:

El gerundio ya en forma única [após a queda da declinação, fica reduzido ao caso ablativo], pasó a desempeñar muchas de las funciones que el latín atribuía al particípio de presente. De este modo, el gerundio, limitado a una sola de sus formas, muy reducidas por tanto sus funciones originarias, las amplía, en cambio, de modo importante, al tomar muchas de las de otra forma verbal [o particípio de presente].

Partindo da premissa chomskiana da estrutura profunda e de superfície, observamos que latim, português e galego exprimem na estrutura profunda a mesma ideia semântica enquanto que na de superfície, o latim apresenta uma forma diferente da partilhada por galego e português; os processos sintáticos divergem. Veja-se o latim comparado com o português e o galego nas principais funções sintáticas em que entram as formas finitas do verbo (as que nos vão permitir entender a formação da perífrase durativa):

\begin{tabular}{|c|c|c|c|c|}
\hline & & Latim & \multicolumn{2}{|c|}{ Português / Galego } \\
\hline Infinitivo & & CANERE & \multicolumn{2}{|c|}{ CANTAR } \\
\hline Gerúndio & \multicolumn{2}{|c|}{ 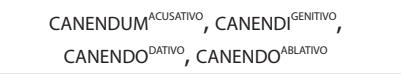 } & \multicolumn{2}{|c|}{$\begin{array}{l}\text { CANTANDO / } \\
\text { A CANTAR }\end{array}$} \\
\hline $\begin{array}{l}\text { Particípio } \\
\text { Presente }\end{array}$ & \multicolumn{2}{|c|}{ CANENS, -TIS } & \multicolumn{2}{|c|}{ CANTANTE } \\
\hline (1§) [sujeito] & \multicolumn{2}{|c|}{$\begin{array}{c}\text { INFINITIVO } \\
\text { Canere mihi placet }\end{array}$} & \multicolumn{2}{|c|}{$\begin{array}{c}\text { INFINITIVO } \\
\text { Cantar faz-me feliz } \\
\text { Cantar faime feliz }^{\mathrm{G}}\end{array}$} \\
\hline (2§) [OD] & $\begin{array}{c}\text { INFINIT } \\
\text { Canere scio }\end{array}$ & $\begin{array}{c}\text { AD+GER }{ }^{\text {Acus }} \\
\text { Ad canendum scio }\end{array}$ & \multicolumn{2}{|c|}{$\begin{array}{l}\text { INFINITIVO } \\
\text { Sei cantar }\end{array}$} \\
\hline (3§) [CN] & \multicolumn{2}{|c|}{$\begin{array}{l}\text { GERÚNDIO GENTIIO } \\
\text { Ars canendi }\end{array}$} & \multicolumn{2}{|c|}{$\begin{array}{l}<D E>+ \text { INFINITIVO } \\
\text { A arte de cantar }\end{array}$} \\
\hline (4§) [Cl/Fin] & \multicolumn{2}{|c|}{$\begin{array}{c}\text { GERÚNDIO DATINo } \\
\text { Pares canendo sumus }\end{array}$} & \multicolumn{2}{|c|}{$\begin{array}{c}<A, \text { PARA }>+ \text { INFINITIVO } \\
\text { Somos iguais para cantar }\end{array}$} \\
\hline$(5 \S)[C C]$ & \multicolumn{2}{|c|}{$\begin{array}{c}\text { GERÚNDIO ABLATVO } \\
\text { Canendo liberi fiemus }\end{array}$} & $\begin{array}{c}\left({ }^{*}\right) \text { GERÚNDIO } \\
\text { Cantando, } \\
\text { viremos a ser livres }{ }^{\mathrm{P}} \\
\text { Cantando, } \\
\text { chegaremos a ser libres }^{\mathrm{G}}\end{array}$ & $\begin{array}{c}<A>+ \text { INFINITIVO } \\
\text { A cantar, } \\
\text { viremos a ser livres }{ }^{p}\end{array}$ \\
\hline (6§) [durativa] & \multicolumn{2}{|c|}{$\begin{array}{l}\text { PART. PRESENTE+ESSE } \\
\text { Canens est }\end{array}$} & $\begin{array}{l}\text { (*) ESTAR+GERÚNDIO }^{\text {Está cantando }}\end{array}$ & $\begin{array}{c}\text { ESTAR+ }<\text { A }>+ \text { INFINIT } \\
\text { Está a cantar }\end{array}$ \\
\hline
\end{tabular}

Tabela 1. Formas finitas no latim, no português e no galego

O presente quadro permite-nos, desde logo, levantar dois tipos de questões: (i) por que nos usos dos falantes portugueses e galegos, se em todas as funções sintáticas ( $1 \S-4 \S)$ utilizam o infinitivo, se mantém também o gerúndio nas funções circunstanciais em português $\left(5 \S\left(^{*}\right)^{1}\right)$ e na estrutura durativa (6§)?, e (ii) por que se substituiu o particípio de presente pelo gerúndio e esse por stare?; e na estrutura <estar + a + infinitivo>, por que triunfou essa preposição e não outra? 


\section{ESTUDO DAS FORMAS FINITAS}

A alteração dos constituintes requer a elaboração de um estudo das formas latinas. Terá especial relevo o gerúndio, com funções sintáticas no latim muito diferentes das que possui hoje nas línguas românicas e semelhantes ao inglês, língua com a qual se comparará (para uma melhor compreensão da sua pretérita função). Ampliar-se-á, deste modo, a comparação com outras línguas românicas, a fim de examinarmos as diferentes ou similares soluções.

Poder-se-á dizer que o infinitivo [INF] é um substantivo verbal (nome de ação) e como substantivo não pode ser declinado, mas como verbo, pode ser conjugado. O gerúndio [GER] é também um substantivo verbal (nome de ação). Como substantivo pode ser declinado, mas como verbo, não pode ser conjugado. O particípio do presente [PP] é um adjetivo verbal que pode ser declinado e como verbo entra em jogo com um verbo em forma finita. Em relação ao INF latino, diz Väänänen (2003: 240): “El infinitivo presente es un antiguo sustantivo, tanto en activa como en pasiva: legere «el acto de leer», legi «el acto de ser leído». Pero el latín ha metido el infinitivo dentro del sistema de la conjugación".

Como verificaremos, não fez assim o inglês, língua à qual recorreremos, já que, se o INF e o GER apresentam essa história, julga-se necessário recuar no tempo e comparar com uma língua também indoeuropeia que ainda mantém o GER com as funções que detinha o latim (e apresenta na estrutura durativa os mesmos constituintes que o latim). Ampliaremos, porém, a comparação, tendo em conta o francês e o espanhol.

Partindo, deste modo, do quadro anterior, mostraremos a sintaxe comparativa das três formas não finitas (inglês / latim $\rightarrow$ francês, espanhol, português/galego):

\begin{tabular}{|c|c|c|c|c|c|}
\hline & Inglês & Latim & Francês & Espanhol & Port. / Galego \\
\hline Infinitivo & TO SING & CANERE & CHANTER & CANTAR & CANTAR \\
\hline Gerúndio & $\begin{array}{c}\text { SINGING } \\
\left(- \text {-ing, }^{- \text {ung }^{x}>}\right. \\
\text {-ing } \\
\text { (XV } \rightarrow)\end{array}$ & $\begin{array}{c}\text { CANENDUM }^{\text {ACUS }}, \\
\text { CANENDI }^{\text {GENIT }}, \text { CANEN- }^{\text {- }} \text { DO }^{\text {DAT/ABLAT }}\end{array}$ & EN CHANTANT & CANTANDO & $\begin{array}{l}\text { CANTANDO / } \\
\text { A CANTAR }\end{array}$ \\
\hline $\begin{array}{l}\text { Particípio } \\
\text { Presente }\end{array}$ & $\begin{array}{c}\text { SINGING } \\
\text { (-ende, }- \text {-inde }^{\mathrm{X}}> \\
\text {-inge }^{\mathrm{XV}}> \\
\text {-ing }^{\mathrm{XVI} \rightarrow} \text { ) }\end{array}$ & CANENS, -TIS & CHANTANT(E) & CANTANTE & CANTANTE \\
\hline $\begin{array}{l}(1 \S) \\
\text { [sujeito] }\end{array}$ & $\begin{array}{c}\text { (A) GERÚNDIO } \\
\text { Singing makes } \\
\text { me happy } \\
\text { (B) INFINIT } \\
\text { To sing makes me } \\
\text { happy }\end{array}$ & $\begin{array}{c}\text { INFINITIVO } \\
\text { Canere mihi } \\
\text { placet }\end{array}$ & $\begin{array}{l}\text { INFINITIVO } \\
\text { II me plaît } \\
\text { chanter }\end{array}$ & $\begin{array}{l}\text { INFINITIVo } \\
\text { Cantar } \\
\text { me hace } \\
\text { feliz }\end{array}$ & $\begin{array}{c}\text { INFINITIVO } \\
\text { Cantar faz- } \\
\text {-me feliz } \\
\text { Cantar faime } \\
\text { feliz }^{\mathbf{G}}\end{array}$ \\
\hline $\begin{array}{l}(2 \S) \\
{[O D]}\end{array}$ & $\begin{array}{l}\text { (A) GERÚNDIO } \\
\text { I love }{ }^{3} \text { singing } \\
\text { (B) INFINIT } \\
\text { I know how to } \\
\text { sing }\end{array}$ & $\begin{array}{c}\text { (A) INFINITIVO } \\
\text { Canere scio } \\
\text { Canere amo } \\
\text { (B) AD+GER. }{ }^{A C} \\
\text { Ad canendum } \\
\text { scio }\end{array}$ & $\begin{array}{l}\text { INFINITIVO } \\
\text { Je sais chanter } \\
\text { J'aime chanter }\end{array}$ & $\begin{array}{l}\text { INFINITIVO } \\
\text { Sé cantar } \\
\text { Amo } \\
\text { cantar }\end{array}$ & $\begin{array}{c}\text { INFINITIVo } \\
\text { Sei cantar } \\
\text { Amo cantar }\end{array}$ \\
\hline $\begin{array}{l}(3 \S) \\
{[C N]}\end{array}$ & $\begin{array}{c}<\text { OF }> \\
\text { +GERÚNDIO } \\
\text { The art of singing }\end{array}$ & $\begin{array}{l}\text { GERÚNDIO GENTIVO } \\
\text { Ars canendi }\end{array}$ & $\begin{array}{c}\quad<D E> \\
\text { +INFINITIVO } \\
\text { L'art de } \\
\text { chanter }\end{array}$ & $\begin{array}{c}\text { DDE } \\
\text { +INFINITIVO } \\
\text { El arte } \\
\text { de cantar }\end{array}$ & $\begin{array}{c}\quad \angle D E> \\
+ \text { INFINITIVO } \\
\text { A arte de } \\
\text { cantar }\end{array}$ \\
\hline $\begin{array}{l}(4 \S) \\
{[C l / F i n]}\end{array}$ & $\begin{array}{c}<\text { TO }> \\
\text { +INFINITIVO } \\
\text { We have the } \\
\text { same capacity } \\
\text { to sing }\end{array}$ & $\begin{array}{l}\text { GERÚNDIO DATIVO } \\
\text { Pares canendo } \\
\text { sumus }\end{array}$ & $\begin{array}{c}\langle\dot{A}, \text { POUR }> \\
+ \text { INFINITIVO } \\
\text { Nous sommes } \\
\text { égales pour } \\
\text { chanter }\end{array}$ & $\begin{array}{c}<A, \text { PARA }> \\
+ \text { INFINITIVO } \\
\text { Somos ig- } \\
\text { uales para } \\
\text { cantar }\end{array}$ & $\begin{array}{c}<A, \text { PARA }> \\
+ \text { INFINITIVO } \\
\text { Somos iguais } \\
\text { para cantar }\end{array}$ \\
\hline
\end{tabular}

${ }^{2}$ Em circunstanciais normais, para exprimir o facto de 'saber' deveria ser can, um modal verb que apenas admite infinitivo sem to. Oferece-se um segundo exemplo com love que admite gerúndio. 


\begin{tabular}{|c|c|c|c|c|c|}
\hline & Inglês & Latim & Francês & Espanhol & Port. / Galego \\
\hline $\begin{array}{l}(5 \S) \\
{[C C]}\end{array}$ & $\begin{array}{c}<B Y> \\
+ \text { GERÚNDIO } \\
\text { By singing we will } \\
\text { become free }\end{array}$ & $\begin{array}{l}\text { GERÚNDIO ABLATIVO } \\
\text { Canendo liberi } \\
\text { fiemus }\end{array}$ & $\begin{array}{l}\text { <EN>+PART. } \\
\text { PRESENTE } \\
\text { En chantant, } \\
\text { nous dévien- } \\
\text { drons libres }\end{array}$ & $\begin{array}{l}\text { GERÚNDIO } \\
\text { Cantando, } \\
\text { nos } \\
\text { haremos } \\
\text { libres }\end{array}$ & $\begin{array}{l}\text { (A) GERÚNDIO } \\
\text { Cantando, } \\
\text { viremos } \\
\text { a ser livres }^{\mathrm{P}} \\
\text { Cantando, } \\
\text { chegaremos a } \text { a libres } \\
\text { ser } \\
\text { (B) }<\text { A }> \\
\text { +INFINITIVO } \\
\text { A cantar, } \\
\text { viremos a ser } \\
\text { livres }^{\mathrm{P}}\end{array}$ \\
\hline $\begin{array}{l}\text { (6§) } \\
\text { [durativa] }\end{array}$ & $\begin{array}{c}\text { TO BE+PART. PRESENTE } \\
\text { He is singing }\end{array}$ & $\begin{array}{c}\text { ESSE+PART. } \\
\text { PRESENTE } \\
\text { Canens est }\end{array}$ & 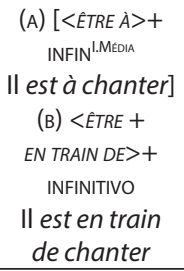 & $\begin{array}{l}\text { ESTAR+ } \\
\text { GERÚNDIO } \\
\text { Está can- } \\
\text { tando }\end{array}$ & $\begin{array}{c}\text { (A) ESTAR+ } \\
\text { GERÚNDIO } \\
\text { Está cantando } \\
\text { (B) ESTAR+ } \\
<\text { A >+INFINIT } \\
\text { Está a cantar }\end{array}$ \\
\hline adjetivo & $\begin{array}{l}\text { Singing man } \\
\text { [Singer] }\end{array}$ & Homo canens & $\begin{array}{l}\text { Homme chan- } \\
\text { tant [chanteur] }\end{array}$ & $\begin{array}{l}\text { Hombre } \\
\text { cantante } \\
\text { [cantor] }\end{array}$ & $\begin{array}{c}\text { Homem / } \\
\text { Home can- } \\
\text { tante } \\
\text { [cantor] }\end{array}$ \\
\hline $\begin{array}{l}(7 \S) \\
\text { part. pres }\end{array}$ & $\begin{array}{c}\text { The man is sing- } \\
\text { ing (6§) }\end{array}$ & $\begin{array}{l}\text { Homo canens } \\
\text { est ( } 6 \S)\end{array}$ & $\begin{array}{l}\text { L'homme est } \\
\text { en train de } \\
\text { chanter }(6 \S)\end{array}$ & $\begin{array}{l}\text { El hom- } \\
\text { bre } \\
\text { está } \\
\text { cantando } \\
(6 \S)\end{array}$ & $\begin{array}{c}\text { (A) O homem } \\
\text { / home está } \\
\text { cantando (6§) } \\
\text { (B) O homem / } \\
\text { home } \\
\text { está a cantar } \\
(6 \S)\end{array}$ \\
\hline
\end{tabular}

Tabela 2. Sintaxe comparativa entre o inglês, o latim, o francês, o espanhol, o português e o galego

Através dos dados esquematizados acima, podemos afirmar que em (1§), com função de sujeito, temos a ocorrência em inglês, do GER e do INF ${ }^{3}$. Em latim, do INF. Nas quatro línguas românicas analisadas temos esta situação. No que respeita ao INF, poder-se-á dizer que é mais tardio em inglês, sendo o GER a forma originária. Muito curiosa é a afirmação de Bassols (2015: 233):

Las formas más antiguas del infinitivo (amare y amari) no son otra cosa que sustantivos verbales fosilizados [...]. En realidad, amare es etimológicamente un locativo, y amari un dativo, casos por medio de los cuales se expresaba originariamente una idea de finalidad. Esta acepción subsiste en latín sólo en algunos giros estereotipados, pues las ya citadas formas asumieron pronto un significado análogo al de un caso recto. Esta evolución se observa también en otras lenguas; así, to love «amar», etimológicamente significa «para amar».

Em (2§), temos a função de OD que nos ocorre em inglês, com GER e INF (sendo de notar que este é a forma mais recente) ${ }^{4}$. Em latim, ocorre o INF (e o GER precedido da preposição ad). Em francês, espanhol, português e galego, temos o INF. De notar que, atualmente, o inglês apresenta o GER em qualquer função sintática (salvo $\mathrm{Cl}$ ). O sujeito e o OD podem ser O GER e O INF, nos restantes casos, como em latim, só o GER (oblíquos, exceto como foi referido na alínea anterior, com o Cl):

To swim is good / Nadar é bom

Swimming is good / O ato de nadar(1) - A natação(2) ${ }^{5}$ - Nadar(3) é bom/boa.

\footnotetext{
${ }^{3}$ No inglês coloquial, aparece, preferencialmente, O GER. O INF pertence a uma linguagem mais culta e filosófica. Por outro lado, O GER costuma indicar a atividade e o INF a ideia abstrata.

${ }^{4}$ Remetemos, igualmente, para a nota anterior.

${ }^{5}$ Em (1) e (2), dá-se uma tradução mais próxima do que exprime realmente o substantivo verbal - GER - inglês e latino.
} 
Podemos afirmar, ainda, que o latim e o inglês não partilham apenas essa característica, como observaremos em (6§).

Em (3§), temos a função de CN que, em inglês, é o GER precedido da preposição of. Em latim, o GER é declinado no caso genitivo. Em francês, espanhol, português e galego, o INF é precedido da preposição de. Em inglês, as funções oblíquas (sempre GER) necessitam de preposição, sendo que, em latim, da declinação do gerúndio. Refere Harto Trujillo (1994: 281): “En definitiva, [...], desde el indoeuropeo existía una especie de sustantivo verbal que permitía 'declinar' el infinitivo".

Quanto a (4§), função de $\mathrm{Cl} \rightarrow$ finalidade, em inglês, o INF é precedido da preposição to (na verdade, o INF em inglês não tem propriedades substantivas - como o latino -, apenas verbais e procede do presente de indicativo [forma básica que contribui com o significado] precedido da preposição que indicava finalidade). Lembre-se, a propósito, a citação de Bassols em (1§). Em latim, o GER quando declinado em caso dativo assume como função principal indicar finalidade, sendo que nas línguas românicas, o INF pode ser precedido da preposição $a$ ou para.

Em (5§), surge a função de CC na qual, em inglês, o GER é precedido da preposição by (originariamente uma partícula adverbial e que foi especializada cedo como preposição à frente do GER para indicar "through the activity or effort of" [Webster's 1998]). Em latim, surge-nos o GER que está declinado em caso ablativo, assumindo valores semânticos modal, instrumental/causal, limitativo, temporal, comparativo. Nas línguas românicas, surge-nos: a) francês: o pp precedido da preposição en (em latim existia in + GER acusativo); b) espanhol: o GER (conservado como tal do latim); PE e galego: o GER (conservado como tal do latim) e em português também a preposição $a+$ INF.

Em (6§), temos uma perífrase durativa em que em todos os casos entra em jogo a cópula. Em inglês, temos to be + PP. Em latim, temos PP + esse. Leia-se, a este respeito, o que refere Bassols (2015: 227):

Participio de presente y verbo copulativo (= scribens sum).

Esta perífrasis tiene un significado muy afín a las formas finitas del verbo simple. En realidad la diferencia entre scribens sum y scribo es muy tenue; a lo sumo podemos decir que el giro perifrástico tiene más fuerza expresiva y atribuye una mayor persistencia y continuidad a la acción.

No caso do inglês atual, é preciso referir que a evolução fonética fez com que hoje o GER e o PP confluam na mesma forma, acabada em -ing e que não devemos confundir: 0 GER: -ing, - ung ${ }^{x}>$ -ing ${ }^{\mathrm{XV} \rightarrow}$ e o PP: -ende ${ }^{6}$,-inde $\mathrm{X}^{\mathrm{X}}>$-inge $\mathrm{eV}^{\mathrm{XV}}>$-ing ${ }^{\mathrm{XVI} \rightarrow}$. Assim:

I like swimming / Natare placet mihi = Gosto [do ato de nadar]-da natação-de nadar

I am swimming / Natans sum = Estou nadando ou Estou a nadar (literalmente, "sou nadante")

Nas línguas românicas, surge, em francês, <être en train de $>^{7}+\mathrm{INF}$, sendo que, na ldade Média, também existia être + PP - como no latim. Existia, igualmente, a estrutura être à + INF que exprimia a mesma ideia do que em português e que atualmente expressa basicamente a mesma ação, mas com uma nuance semântica de ação sem pausa, intensa, isto é, de pouco uso (cf. Mortimer 2005). Em espanhol, temos estar + GER e, em português e galego, ocorre estar + GER / estar + preposição $a$ + INF. Já no latim vulgar se verifica um uso cada vez mais pronunciado da estrutura stare + GER ablativo, ainda próxima de PP + esse (cf. Bertinetto 2000). Embora o PP se conservasse na Idade Média, usado como adjetivo com o verbo esse, a identificação do pp com o GER foi tal que, depois de se generalizar, foi usado com verbos de estado e movimento (esse, stare, ire, venire), de onde procedem as perífrases de GER (Lausberg 1981; Väänänen 2003). A propósito, afirma Diez (1836-1844, III: 237):

Nous avons vu en parlant de l'infinitif que le gérondif a dû céder a ce mode dans toutes les fonctions dont il était chargé. Il a cependant conservé une de ses formes, l'ablatif; car la syntaxe démontre assez que l'it., esp cantando, le français chantant procedent de ce cas et non d'un autre.

${ }^{6}$ Forma conservada hoje em holandês e alemão (De Vliegende Hollander / Der Fliegende Holländer [The Flying Dutchman]-[O holandês voador]).

${ }^{7}$ Ainda que o valor principal seja o de déroulement de l'action, pode apresentar outros valores, nomeadamente o incoativo. 
A preposição $a$ procede basicamente da preposição latina ad (e em alguns casos de $a b$ ) que indicava aproximação, início de uma ação, movimento em direção a um lugar no espaço ou no tempo, proximidade, coincidência no tempo ou no espaço, entre outros valores, os quais se adequam à estrutura com infinitivo, tal como desenvolve Brea (1985).

Se for ampliada a comparação da perífrase durativa a outras línguas românicas (de ocidente a oriente), observa-se que a estrutura com INF (e a preposição $a$ ) não é exclusiva das línguas portuguesa e galega, tal como mostra o esquema seguinte:

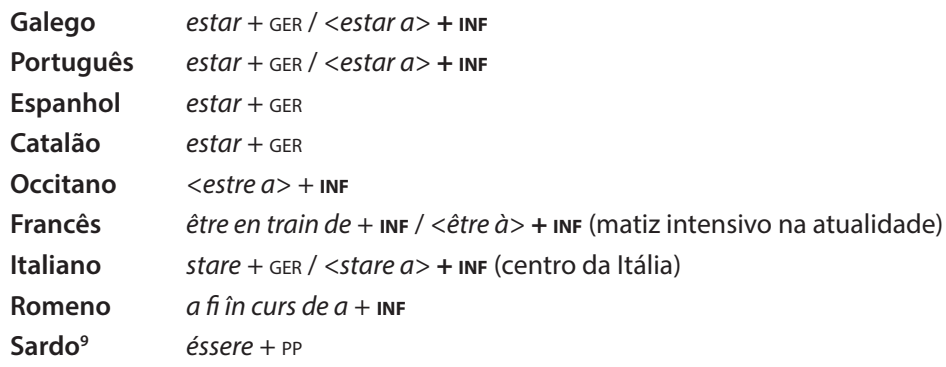

No galego padrão atual acontece a mesma situação que no $\mathrm{PE}$, embora a perífrase com infinitivo seja, inicialmente, dialetal, tal como refere Fernández Rei (1991: 104): "ten unha xeografía compacta nos falares pontevedreses do bloque occidental, se ben non é exclusiva".

Quanto a (7§) PP, em estreita relação com (6§), apenas é apresentada para se observar a diferente função do pp nas suas duas funções: a de adjetivo (na atualidade) e a de verbo (em épocas passadas) ${ }^{9}$. Na segunda, é substituído pelo GeR em espanhol, português e galego. Há já, desde os inícios das línguas românicas, documentação do fenómeno, no âmbito hispânico, como, por exemplo, nas Glosas Emilianenses e Silenses (carens $\rightarrow$ lebando; absente $\rightarrow$ luenge stando; qui... ignorans $\rightarrow$ qui... non sapiendo; revertente $\rightarrow$ retornando). Afirma Meyer-Lübke que "el ablativo de gerundio ocupó cada vez más el lugar del participio de presente, mientras que éste, de participio pasó a mero adjetivo verbal" (1926: 321). Em relação a esse aspeto (5§), o GER foi ampliando a sua função instrumental-modal originária (secundariamente também podia indicar uma ação concomitante com a principal) para outras formas já consolidadas, nomeadamente causal, condicional, concessiva, opositiva, final e temporal com diversas significações.

Assim, temos para a noção semântica do ato de cantar as seguintes possibilidades sintáticas:

\begin{tabular}{|c|c|c|c|c|c|}
\hline SUJ: & $\begin{array}{c}\text { Ing. } \\
\text { GER / (INF) }\end{array}$ & $\begin{array}{l}\text { Lat. } \\
\text { INF }\end{array}$ & $\begin{array}{l}\text { Fr. } \\
\text { INF }\end{array}$ & $\begin{array}{l}\text { Esp. } \\
\text { INF }\end{array}$ & $\begin{array}{l}\text { Port./Gal. } \\
\text { INF }\end{array}$ \\
\hline CD: & GER / (INF) & INF / $A D+$ GER & INF & INF & INF \\
\hline CN: & $O F+$ GER & GER GENTIVO & $D E+I N F$ & $D E+I N F$ & $D E+I N F$ \\
\hline $\mathrm{Cl} /$ Fin: & $T O+I N F$ & GER DATIVO & $\grave{A}, P O U R+I N F$ & $A, P A R A+I N F$ & A, PARA + INF \\
\hline CC: & $B Y+\mathbf{G E R}$ & GER ABLATIVo & $E N$ + PART. PRES. & GER & GER / $A+$ INF \\
\hline
\end{tabular}

Essa semântica materializa-se no NOMEN ACTIONIS, o substantivo verbal por excelência nas línguas indoeuropeias, o GER. Existia um dativo que exprimia finalidade, passando depois a funcionar como variante do GER, O INF:

a. a língua inglesa mantém quase inalterado esse sistema;

b. a língua latina consolida o INF na função de SUJ (e de CD opcional); o resto fica inalterado;

c. a língua francesa herda o INF latino no SUJ e no CD; perde O GER nas restantes funções que é trocado pelo INF salvo no CC;

d. a língua espanhola consolida o INF em todas as funções salvo no CC, em que se mantém O GER;

\footnotetext{
${ }^{8}$ De notar que a língua sarda herdou inalterada a estrutura latina.

${ }^{9}$ Restam, hoje, alguns particípios de presente, fossilizados com valor (semi)verbal: água corrente, câmara ardente, etc.
} 
e. as línguas portuguesa e galega consolidam o INF em todas as funções; na de CC também se mantém o GER;

f. todas as línguas, em maior ou menor medida, precisam da preposição nas funções oblíquas.

Na perífrase durativa observam-se as seguintes estruturas:

$\begin{array}{ccccc}\text { Ing. } & \text { Lat. } & \text { Fr. } & \text { Esp. } & \text { Port./Gal. } \\ \text { TO BE }+ & \text { ESSE }+ & \text { ETRE + EN TRAIN DE + INF } & \text { ESTAR + GER } & \text { ESTAR + GER / } \\ \text { PART. PRES. } & \text { PART. PRES. } & & & \text { ESTAR + A + INF }\end{array}$

a. As línguas inglesa e latina mantêm o verbo auxiliar (a cópula: to be / esse) e o verbo principal aparece sob a forma do PART. PRES.;

b. a língua francesa mantém o verbo auxiliar (a cópula: être) seguido do sintagma preposicional en train de ('no andamento de') e no verbo principal substitui o PART. PRES latino pelo INF;

c. a língua espanhola perde a cópula latina e utiliza a cópula românica estar como verbo auxiliar; o verbo principal é o GER, não herda O PART. PRES. Latino;

d. as línguas portuguesa e galega apresentam uma dupla possibilidade: (i) a mesma situação que o espanhol e (ii) o verbo auxiliar continua a ser estar, mas o principal é o INF antecedido pela preposição $a$.

\section{As estruturas EM FOCO NO PORTUGUÊS EUROPEU, BRASILEIRO E NO GALEGO}

Com todos estes dados, tentar-se-á justificar a existência das duas estruturas sintáticas com semântica sinonímica e, consequentemente, a cronologia dos factos: de acordo aos registos escritos (desde o século XIII até à atualidade), pretendemos observar qual a mais antiga e qual a que aparece posteriormente; qual a frequência de uso no PE, no PB e no galego, de cada uma delas.

Observámos como o particípio de presente latino foi substituído pelo caso ablativo do gerúndio na construção da estrutura durativa. Essa foi a forma primitiva documentada nas línguas portuguesa e galega. Regista-se, hoje, igualmente, a estrutura do infinitivo gerundivo. Uma hipótese para tentar justificar essa forma seria a da analogia (segundo a posição de Brocardo, 2008): se todos os casos latinos do gerúndio - exceto o ablativo - foram substituídos pela preposição correspondente mais o infinitivo (na sequência de o infinitivo ser o caso nominativo, sujeito), também o ablativo pôde começar a ser substituído pela mesma construção preposicional.

A estrutura do gerúndio foi mantida e apresentada como a correta pelas gramáticas de todas as épocas, sem se mencionar a do infinitivo gerundivo (só a partir do século XX será tratada); os dados recolhidos por Maler (1973) levam-nos a afirmar que era uma estrutura entendida como popular e apenas escrita em situações pouco cultas ou populares. Por outro lado, e indicando uma outra hipótese que tem em conta informação apenas dos séculos XIX e XX, Mothé (2007) opôs estruturas perifrásticas com verbo auxiliar (com gerúndio: está cantando) a estruturas sintéticas com verbo pleno (com infinitivo gerundivo: está a cantar). Pretende investigar se uma dessas duas formas privilegiava o uso de uma estrutura ou de outra, e ainda se as estruturas perifrásticas privilegiaram o avanço do infinitivo gerundivo, observando quais verbos auxiliares contribuíram para esse avanço. Feita a pesquisa, conclui, assim, que as construções perifrásticas (verbo auxiliar + verbo principal), particularmente as que se constituem por um verbo auxiliar como estar, andar, ficar - que são, por sua vez, aquelas utilizadas para formar as durativas -, são as que mais favorecem o uso de infinitivo gerundivo em construções analíticas. Os resultados atingiram mesmo as estruturas sintéticas. Após uma época de flutuação, verifica-se que, em Portugal, durante o século XX, culminou o processo com o triunfo do infinitivo gerundivo (a preposição 'a' perdeu o seu valor inicial e gramaticalizou-se, funcionando 
como um afixo do verbo que serve para formar aspeto durativo). As duas perspetivas poderiam vir a complementar-se.

No que diz respeito à cronologia do fenómeno, já Maler (1973: 250) afirmara que:

On sait, d'une part, qu'il n'y a guère de preuves de l'emploi de l'infinitif gerondival avant l'époque de Gil Vicente. D'autre part, nul n'ignore qu'au moins en ce qui concerne le type estar a brincar, il a plus ou moins délogé, dans le portugais actuel ordinaire [le portugais européen], la 'conjugação perifrástica' avec 'gerúndio' (p. 250).

O investigador faz uma busca pelas obras anteriores a Gil Vicente, referindo que apenas encontrou casos da construção gerundiva, sendo esses com o verbo andar maioritariamente. Não encontra a construção na obra de Camões pelas razões, precisamente, acima aduzidas. Encontra-se em Gil Vicente, mas não de modo geral. Volta a afirmar, na p. 256, que "On sait que le début de l'i.g. est de date relativement récente, le xvle siècle". Contudo, e seguindo o costume linguístico, considera que na língua falada deve ter começado muito antes. Encontra algum caso no século xvIII, nas obras de António José da Silva (O Judeu) mas [o i.g.] "c'est un néologisme qui sent encore un peu trop les bas-fonds et qu'on est gêné d'admettre dans le monde des lettres" (p. 265). E, por fim, a grande eclosão encontra-a no século xIx:

Ce ne sera que avec le Romantisme et, sourtout, avec le Réalisme et le Naturalisme que l'infinitif l'emportera sur le gérondif traditionnel, c'est-à-dire les mouvements littéraires qui, dans les dialogues en particulier, ouvriront à deux battants les portes à la langue populaire et donneront libre accès à ce parvenu de la grammaire, l'infinitif gérondival (p. 268).

$\mathrm{Na}$ altura em que Maler efetuou a pesquisa não havia corpora linguísticos. Na atualidade, esses recursos permitem-nos fazer afirmações com maior rigor. Tentaremos ver se os dados fornecidos pelo autor sueco correspondem, ou não, aos encontrados neste estudo (dados, por outra parte, partilhados pelo comum dos filólogos, que apontam para um registo escrito tardio da estrutura durativa em foco).

Para a análise dos dados, utilizaremos vários corpora, tanto do português como do galego, nomeadamente o CIPM (Corpus Informatizado do Português Medieval - Faculdade de Ciências Sociais e Humanas da Universidade Nova de lisboa - http://cipm.fcsh.unl.pt/) ${ }^{10}$, o CdP (Corpus do Português - Davies e Ferreira - http://www.corpusdoportugues.org), o TMILG (Tesouro Medieval Informatizado da Lingua Galega - http://ilg.usc.es/tmilg/index.php), o TILG (Tesouro Informatizado da Lingua Galega - http://ilg.usc.es/TILG) e o CORGA (Corpus de Referencia do Galego Actual - http://corpus.cirp.es/corga).

Os dados do CIPM ${ }^{11}$ revelam-nos para o português arcaico (séculos XIII-fins XVI), 75\% para a perífrase <estar + a + infinitivo > e 25\% para a perífrase <estar + gerúndio > (no século XIII aparece com frequência o auxiliar andar). Vejam-se alguns exemplos:

E, assy fazendo esto, algûas vezes acontecia que adormecia o Cide em cima de hûû scano ë que estava a comer (Crónica Geral de Espanha, 1344);

Quando aqueles que estavam a ouvir este conto entenderom que aquel era Erec, filho de rei Lac e que de tam longas terras se fezera levar, começou-se entom o doo tam grande e tam fero como se todos seus amigos tevessem mortos ante si (A Demanda do Santo Graal, cópia do século XV);

[...] \& uos auerdes os dous terços por uoso lauor \& collerdes o dito pan \& bjño pelo mõje \& home do dito mosteyro \& dardes de comer \& de beber aaquel que porlo dito mosteyro esteuer a coller o dito pã \& byño en quanto se coller \& byndimar" (Textos Notariais. História do galego-português, 1401-1500).

\footnotetext{
${ }^{10}$ Para o período medieval, optámos por este corpus, em virtude de haver grande rigor na edição das fontes. Se consultarmos o CdP para o mesmo período, verificamos uma divergência na documentação e nos critérios de edição, pelo que não nos é tão útil para este trabalho.

${ }^{11}$ O CIPM é constituído por textos literários e não literários, sendo que os textos literários são em poesia ou prosa. Quanto aos textos não literários, abundam fundamentalmente textos notariais, datados e localizados, o que nos dá uma grande segurança para o estabelecimento da cronologia do fenómeno em análise. Para a visualização de todo o corpus, cf. http:// cipm.fcsh.unl.pt/.

Os dados a que chegámos são dados com fiabilidade, em virtude de terem sido objeto de contagem manual (o corpus não é lematizado), constituindo, assim, um dado novo para a história do português e que vem marcar a possibilidade de investigações futuras. Os exemplos aduzidos no texto são apenas meras ilustrações de algumas das construções encontradas. De referir ainda que a maioria dos exemplos localizados dizem respeito a textos em prosa e a textos notariais, verificando-se pouca expressão da estrutura em textos poéticos, o que é natural dada a estrutura linguística e a tradição manuscrita dessa tipologia textual.
} 
E logo D. Fernando de Vasconcelos, bispo que entao era de Lamego e capelao-mór del-rei, tomou juramento à ifante que cumpriria tudo o que à sua conta estava a fazer pera bem daquele contrato (Frei Luís de Sousa, Anais de D. Joao III, 1631).

[...] e se lhe satisfizesse o que constasse se Ihe estava a dever, porquanto me fazia queixa o dito Manoel de Mendonça [...] (Diario do Conde de Zarzedas, XVII).

Que estás coidando? O que estás coidando? (Vidas de Santos de um Manuscrito Alcobacense, 1200-1300);

[...] estava cantando missa, com'avia costumado, (Cantigas de Santa Maria, Afonso X, S. XIII);

Andam ant'el chorando mil vegadas (Cantiga de escárnio e mal dizer, S. XIII).

[...] e o treedor, quando os vyo, sayu a os receber e disselhes como avya tres dias que os estava atendendo (Crónica Geral de Espanha de 1344).

Para obter dados relativos à época entre os séculos XVI e XX, considerámos o CdP. Cumpre dizer que foram procuradas apenas as sequências <est* $+a+$ infinitivo $>$ e <est* + gerúndio $>$ sem ter em conta possíveis estruturas em que apareçam outras palavras entre o verbo auxiliar e $[\mathrm{a}+\mathrm{INF}]$ ou $[\mathrm{GER}]^{12}$.

No século XVI, foram encontradas 21 ocorrências do infinitivo gerundivo e 295 do gerúndio; no século XVII, 21 para [a + INF] e 288 para [GER]; no século XVIII, 29 para [a + INF] e 186 para o [GER]. Esses dados indicam que, durante o período clássico, <est* $+a+$ infinitivo $>$ representa o 8,5\% dos casos e $<$ est $^{*}+$ gerúndio $>0$ 91,5\% restante. Eis alguns exemplos:

[...] chouia muito rijo, \& ella que estaua a fiar, ouuindo a chuua, cõpadecëdose do marido, que a tal tëpo andaua fora" (Contos \& historias de proveito \& exemplo, Gonçalo Fernandes Trancoso, 1575);

Visto pellos outros cinco ou seis gentios este caso, vieram com grande pressa de mais de hûa legoa ao lugar onde eu estava a rogar lhes pregasse \& os quisesse bautizar antes que o demonio tambem os atormentasse (Cartas dos jesuítas, Padre Amador Rebello, 1588);

Embaixadores mandaraõ dizer a Antonio de Faria, que como a Rey do mar lhe pedião que debaixo do seguro de sua verdade os quisesse emparar, para poderem sayr daly onde estauão a fazer suas viagës (Peregrinação, Fernão Mendes Pinto, 1603);

[...] e só quem sabe quanto depende o remédio e ajuda destes homens do serviço dos índios, que tinham por escravos, e quem viu quão resolutos e obstinados estavam a defender seus cativeiros, com o sangue (Cartas, Padre António Vieira, 1626-1692);

[...] e os mesmos pais de uma rapariga, se lhe pergunta uma pessoa, que os venha visitar, quem é aquele estudante que está a conversar à janela com a filha (Cartas do Abade António da Costa, Antonio da Costa, 1744);

Sendo horas de começar o jogo na Assembleia, se recebeu fàcilmente o conselho da condessa de Laval, tanto mais que estavam a entrar os cavalheiros (Cartas, Cavaleiro de Oliveira, 1756);

Clérigo - Ora sus que estais fazendo? Danor - Ò diabo que t'eu encomendo e quem tal poder te dá (Exortação da Guerra, Gil Vicente, 1514);

Quero-me chegar a el-Rei meu Pai, que já me está vendo (El-Rei seleuco, L. de Camões, 1445); Estou vendo que se o negócio não é invenção (Cartas, Padre António Vieira, 1626-1692);

[...] pregando-se o Evangelho a tantas nações que o estão pedindo (Discursos vários políticos, Manuel Severim de Faria, 1631);

[...] quando nos parece que está lendo na Gazeta as notícias de Londres ou de Paris (Cartas familiares, Cavaleiro de Oliveira, c1736);

[...] estamos vendo acabar-se a nossa vida (Reflexão sobre a vaidade, Matias Aires, 1743).

Já no português contemporâneo é preciso diferenciar entre a produção escrita em Portugal e a escrita no Brasil, verificando-se, no século XIX, 410 ocorrências para [a + INF] (360 Pg / $50 \mathrm{Br}$ ) e 1.607 para o [GER] (dois terços Pg / um terço Br). No geral, 20\% para [a + INF] e $80 \%$ para [GER]; por países: em Portugal, 25\% para [a + INF] e 75\% para [GER], no Brasil, 8,5\% para [a + INF] e 91,5\% para [GER].

${ }^{12}$ Como nos exemplos seguintes: "Ai, o que está ele a fazer?" (Os Irmãos das Almas, Martins Pena, 1846). “[...] o que me dizem está actualmente fazendo um homem douto meu conhecido" (Verdadeiro Método de Estudar, L. António Verney, 1765). 
No século XX, 2.571 ocorrências (2.547 Pg / $71 \mathrm{Br}$ ) para [a + INF] e 5.065 (206 Pg / $4.859 \mathrm{Br}$ ) para o [GER]. Em termos globais temos 34\% para [a + INF] e 66\% para [GER]; por países: em Portugal, 92,5\% para [a + INF] e 7,5\% para [GER], no Brasil, 1,4\% para [a + INF] e 98,6\% para [GER].

De dados do PE e do PB atuais, de discurso oral espontâneo, para um outro estudo que estamos a desenvolver, foi possível, ainda que de forma pouco rigorosa (porque a finalidade desse trabalho não é analisar este tipo de estruturas), contabilizar para o PE 99\% de usos de <estar + a + infinitivo ${ }^{13}>$ e, para o PB, $97 \%$ de usos de <estar + gerúndio $>$.

Recuando, novamente, ao português antigo, poder-se-á dizer que os dados do CIPM revelam que as estruturas perifrásticas com infinitivo vão diminuindo relativamente às construções com gerúndio nos séculos posteriores (dados do $\mathrm{CdP}$ ) para voltar a aparecer com maior expressão no século XX. Em

E ally estava hu u scudeiro daquelle cavaleiro que estava ouvyndo as missas, que lhe tiinha o cavallo aa porta da igreja e o escudo e a lança (Crónica Geral de Espanha, XIV)

temos sintaticamente uma regência direta; em

E assy estavo estragando toda a terra, em tal guysa que fogya toda a jente co o apertame to da guerra (Crónica Geral de Espanha, XIV),

temos igualmente regência direta e, no exemplo seguinte, surge-nos sintaticamente uma regência indireta:

E, assy fazendo esto, algu as vezes acontecia que adormecia o Cide em cima de hu u scano e que estava $a$ comer (Crónica Geral de Espanha, XIV)

No referente à língua galega, obtiveram-se os dados que a seguir se indicam. No TMILG ${ }^{14}$ aparecem algumas ocorrências com a estrutura <est* + gerúndio $>$, mas não com a preposição e o infinitivo. Eis alguns exemplos:

Quand'eu cheguei, estava el chorando | e non folgava o seu coraçon, | cuidand'en mi, se iria, se non, | mais, pois m'el viu u m'estava asperando, | foi el tan ledo que, des que naci, | nunca tan led'ome con molher vi." (Lírica profana, Juião Bolseiro, 1240-1300);

Moir', amiga, desejando | meu amigu', e vós no vosso | mi falades, e non posso | estar sempr'en esto falando; | mays queredes falar migo?|" (Lírica profana, Pedr'Amigo de Sevilha, 1240-1300);

E ar todavia || sempr'estás lidando || por nos a perfia || o dem'arr[anc]ando, || que, sossacando, || nos vai tentando || con sabores rafeces; || mas tu guardando || e anparando || nos vas, poi-lo couseces.|| (Prosa literária, Afonso X, 1264-1284);

Ca por vos nõ mẽtyr, bem se estauã cõbatẽdo en mays de duzẽtos lugares (Prosa literária, Afonso X, 1350-1399);

Logo que os apostollos forõ tornados a Iherusalem, avẽo asi que San Tome apostolo estaua preegando en hũa çidade a moytas gentes (Prosa religiosa, Anónimo, 1390-1420);

Sepan todos como eu o mariscal Suero Gomez Vasallo dos Reies nosos señores que presente estou jazendo doente daquela Dolencia é enfermedad que Deus tobo por Ven de me dar, E temendo me da morte natural... (Prosa notarial, testamento; Gomes dayaso, 1485).

Para obter dados dos séculos XVI, XVII, XVIII e XIX, usámos o TILG. Este corpus apenas oferece a possibilidade de fazer buscas básicas sem poder usar dados booleanos e a pesquisa torna-se difícil para o nosso propósito. Há infindas ocorrências da construção com gerúndio desde 1671 (procurámos uma forma muito usada 'facendo': “Este, ¿Qué estará facendo?", Entremés famoso sobre da pesca do río Miño, Feixoo de Araúxo) até 1974; para a estrutura do infinitivo, fizemos a

\footnotetext{
${ }^{13}$ De notar que na zona alentejana, em Portugal, se verificam usos com gerúndio.

${ }^{14}$ Este corpus compreende textos desde o ano 700 a 1600. A data mais antiga da estrutura <est* + gerúndio> é a de 1240. 
busca [está a] e obtivemos dados desde 1853 até 1974: de 1853 a 1900, 11 ocorrências; de 1900 a 1950, 50 ocorrências; de 1951 a 1974, 120 ocorrências.

Contudo, devemos referir que, em galego (assim como em português), a estrutura <estar + a + infinitivo> tem dois valores, como recordam Álvarez e Xove:

Como pode observarse, algunhas perífrases coa mesma expresión poden corresponder a varias categorías ou subdivisións: ir + Inf. pode ser temporal de posterioridade, aspectual de fase inminencial ou aspectual de colocación demarcativa; acabar de + Inf. pode ser temporal de anterioridade ou aspectual de fase terminativa; estar $a+$ Inf. pode ser aspectual de fase central (en alternancia con estar + Xer.) ou aspectual de fase inminencial (en alternancia con estar para + Inf.) (2002: 339).

Eis alguns exemplos (dos 181; 5 deles [aspetual de fase iminencial]) representativos desses anos:

E as bágoas unha por unha Virán por miñas faceiras Como doas contadeiras Que pasa o que está a rezar; Así se queixaba un vello $\mathrm{Na}$ Igrexa (Contos da aldea que parecen historias da vila e historias da vila que parecen contos da aldea, Pintos, Juan Manuel, 1858);

Adiós San Miguel curioso que tés dous Santos de ver deitados, parez qu'un dorme, e que o outro está a morrer ("Contestación...," "Traducción...," "Recramo", Pintos, Juan Manuel, 1859). [aspetual de fase iminencial];

O resprandor da lúa Vertes undoso na rexión do mar; A fronda ri garbosa coa lus súa. Dorme Frora ; i o lobo está a ouvear... (Poemas gallegos seguidos d'un tratado sobr'o modo de falar é escribir con propiedade ó dialeuto, Martínez González, Manuel, 1883);

Si o ano qu'está a chegar com'o plesente ha de ser, non sei en qu'hemos parar (Cousas d'a aldea, versos gallegos, Pereira, Aureliano, 1891). [aspetual de fase iminencial];

Teñen, si, a obrigación de queré-los e respetá-los, e ti es moi amantiña con nós. O noso Cidre está a chegar, faredes casamento e daquela xa serás filla nosa de verdá ... (Esclavitú. Drama en dous actos en prosa, Lugrís Freire, Manuel, 1906). [aspetual de fase iminencial];

Arranxa roupa, viño e sustancia para qu'ela que está a chegar e non coas maus baleiras" (Nós. Boletín mensual da Cultura Galega, $n^{\circ} 8$ (24 de decembro de 1921). [aspetual de fase iminencial];

Chove. Está a chover manseniña, docemente, coesa soavidade de agarimo (Nós. Boletín mensual da Cultura Galega, no 17 (1 de marzo de 1923);

¡Doña Sabela, portando o indulto rexio está a chegar! (O Mariscal. Lênda tráxica, Cabanillas, Ramón / A. Villar Ponte, 1926). [aspetual de fase iminencial];

Vostede non sabe o que está a decer, meu pai, olle que millor currunchiño ca este non o hai por todas estas redondezas (Contos, Ventín Durán, José Augusto, 1939);

-E que tamén eu teño medo de que o que está a facer conmigo sexa somentes por lástema, e non por agarimo ... (jMal ollo! Comedia de ambente mariñeiro en 2 aitos e un intermedio, González Tiradas, Cándido Alfonso, 1954);

[...] pondo-me as cousas diante coa nidieza de quen está a ollá-las, como o que as repite xa canso de as repetir (Os biosbardos, Blanco Amor, Eduardo, 1962);

¡Olla o que está a lere somellante babión ...! Deixa que veña ... (Teatro pra a xente, Blanco Amor, Eduardo, 1974).

Segundo o CORGA, de 1975 até à atualidade, foram encontradas 11.196 ocorrências da es-

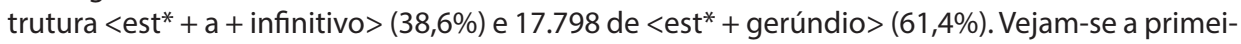
ra e a última ocorrências dos dois casos:

$\mathrm{Si}$, era como unha frol do deserto que estaba a abrir, sedenta, i esperaba recibir tamén a auga fecundadora..." ( $A$ morte de Frank González, Fernández Ferreiro, Xosé, 1975);

Pérez Alonso está a 'peregrinar' de novo a Santiago a través da ruta inglesa mostrando os cadros inspirados na primeira andaina (De Luns a Venres, xornal; Cora, Diego de, 2013);

Pensamos que en boa medida a Igrexa galega é consciente deste reto que lle lanza o presente, e que no seu Concilio Pastoral está tentando darlle unha resposta adecuada (A fe cristiá ante a cuestión da lingua galega, Araúxo Iglesias, Miguel-Anxo, 1975);

Cando practicamente se lle está pondo no peto o diñeiro, dicíndolle que todo era bo, que isto era unha forma de aforrar... (De Luns a Venres, xornal; Cora, Diego de, 2013). 


\section{Considerações finais}

No presente estudo, sobre as construções durativas, formadas pelo verbo auxiliar (estar) mais gerúndio ou pelo verbo auxiliar (estar) mais a preposição 'a' e um infinitivo, julgamos ter alcançado os objetivos gizados:

- Tratar de descrever a existência de duas estruturas semanticamente iguais em português e em galego: <estar + gerúndio > (1) e <estar + a + infinitivo > (2); o latim, a língua de procedência, apenas tinha uma e com constituintes diferentes <particípio de presente + esse $>$. Dados do próprio latim vulgar demonstram a substituição progressiva do particípio de presente (-nte) pelo gerúndio (-ndo) e do verbo esse por estare que gerará a perífrase <estar + -ndo> (3); por sua vez, o gerúndio latino apresenta-se estreitamente relacionado com o infinitivo: este só podia ser, sintaticamente, sujeito ou CD; as restantes funções sintáticas eram desempenhadas pelo gerúndio declinado. Após o desaparecimento da declinação, todas as funções sintáticas são desempenhadas pelo infinitivo antecedido de preposição $(\mathrm{CN} \mathrm{e} \mathrm{Cl})$, exceto $\mathrm{CC}$, que conserva inalterado o gerúndio (sob a morfologia do antigo caso ablativo).

$\mathrm{Na}$ estrutura (1) do português e do galego aprecia-se a continuação da estrutura do latim vulgar (3); para a existência da estrutura (2) referimos duas hipóteses: (i) a formação por analogia com as estruturas românicas [preposição + infinitivo = CN, Cl] e (ii), a hipótese de Mothé (2007), que no seu estudo conclui que as construções perifrásticas (verbo auxiliar [estar, andar, ficar] + verbo principal) são as que favorecem o uso de infinitivo gerundivo em construções analíticas, atingindo também as estruturas sintéticas; em Portugal, durante o século XX, acabou triunfando o infinitivo gerundivo.

Por outro lado, pode ser levantada a questão da não existência de analogia nas outras línguas que mantêm o GER. Na verdade, depois do desaparecimento da declinação, verificamse, nas línguas românicas, poucos vestígios desse esquema (alguns nominativos nos nomes próprios Carlos, Domingos... algum genitivo - nomeadamente nos apelidos, Rodrigues, Gonçalves... - e pouco mais), mas, conservam-se o gerúndio no ablativo e o paradigma dos pronomes pessoais átonos, formas, aliás, muito usadas e de grande produtividade na língua, facto que sustentaria a sua conservação: a utilização habitual que faz com que se preservem quase inalterados.

— No que respeita à cronologia dos factos, através da análise dos corpora já referidos, obtiveram-se os seguintes dados:

a) Para a língua portuguesa:

(i) $<$ estar + a + infinitivo $>$

Ss. XIII-XVI (CIPM) 75\% > XVI-XVIII (CdP) 8,5\% > XIX-Pg (CdP) 25\% > XX-Pg (CdP) 92,5\%. $\mathrm{XIX-Br}(\mathrm{CdP})$ 8,5\% > XX-Br (CdP) 1,4\%.

(ii) $<$ estar + gerúndio >

Ss. XIII-XVI (CIPM) 25\% > XVI-XVIII (CdP) 91,5\% > XIX-Pg (CdP) 75\% > XX-Pg (CdP) 7,5\%. XIX-Br (CdP) 91,5\% > XX-Br (CdP) 98,6\%.

É de sublinhar o facto de, durante a Idade Média, (i) ser a estrutura mais frequente (75\%) [e, hoje, em Portugal ser a estrutura mais utilizada na escrita]; regista-se também a descida significativa durante o português clássico $(8,5 \%)$ e o progressivo aumento durante o século XIX (25\%) até à atualidade, de expressiva maioria (92,5\%).

No Brasil, a tendência do século XIX é a mesma dos séculos anteriores $(8,5 \%)$ e, na atualidade, uma representação quase testemunhal (1,4\%). 
A estrutura herdada do latim românico (ii) apresenta dados contrários: poucos registos durante a Idade Média (25\%), de uso quase exclusivo no português clássico (91,5\%), ligeira descida no século XIX (75\%) e uma queda significativa durante o século XX (7,5\%).

No Brasil, durante o século XIX, continua a tendência dos séculos anteriores $(91,5 \%)$ e cresce até ser quase a única forma usada na atualidade (98,6\%).

Contudo, o PE, a par da expressão com gerúndio, de uso universal, conhecia, desde os primórdios da língua, a fórmula <estar $+a+$ INF $>$.

No caso particular do português, que em Portugal predomine uma perífrase e no Brasil outra, parece que se prende com dois aspetos:

i. o princípio geral da economia da linguagem: não parece viável que existam simultaneamente duas estruturas durativas idênticas semanticamente. Uma das duas acaba por desaparecer (caso do francês <être + PP $>$ ), por ter menor uso (ou usada numa variedade e não em outra PG <estar + a + INF> / BR <estar + GER>), por ser dialetal (o caso do italiano de Roma <stare $+\mathrm{a}+\mathrm{INF}>$ ) ou, ainda, por especializar-se com outro valor (o caso francês de $<$ être + à + INF $>$ ). O espanhol mantém apenas uma <estar + GER>.

ii. considerações sociolinguísticas: se seguirmos a máxima de Bartoli (1928), a língua conserva-se, geralmente, mas nem sempre em todos os aspetos, numa fase mais conservadora nos lugares onde é levada e evolui mais rapidamente no lugar de origem. No Brasil, a pressão da norma fez com que desde os inícios se preservasse a estrutura com gerúndio. Em Portugal, as correntes literárias e sociais abriram a porta na escrita à estrutura gerundiva (Maler 1973). E como conclui Mothé (2014, VIII), que estudou na sua tese o avanço do infinitivo gerundivo através de corpora do género'noticias', textos: "Os resultados obtidos sugerem que o avanço do infinitivo gerundivo no PE foi mais significativo em três diferentes fases ao longo do século XX: na virada da década de 1920 para 1930; depois, na virada da década de 1950 para 1960; e ao fim do século XX, entre as décadas de 1980 e 1990".

b) Para a língua galega:

Observou-se inexistência escrita de <estar $+a+$ infinitivo > até ao século XIX. A partir dessa altura, a perífrase, inicialmente dialetal, começa a ser registada na língua padrão, tendo muita incidência nos últimos decénios, nos quais se vê consolidada. Contudo, na atualidade, ainda representa apenas o $38,6 \%$ dos casos.

Em suma, poder-se-á referir que em português, existia, como foi demonstrado através dos dados, a estrutura <estar + a + infinitivo >, desde o século XIII ao XVI, de forma maioritária. A partir do XVII diminui (a norma consolida na escrita como forma oficial <estar + gerúndio >). No século XVIII, predomina o uso da construção perifrástica através do GER, em vez da construção atual com o INF regido da preposição $a$. No século XIX, a situação é semelhante (cresce timidamente como resultado da maior liberdade na escrita das tendências orais) e, no século XX, salvo em zonas dialetais, reverte e, claramente, no padrão, a forma que prevalece é a da preposição + o infinitivo.

No $\mathrm{PB}$, tendo em conta os dados do século XXI, claramente de expressiva maioria para o gerúndio, aparecem-nos, no século XIX, cerca de 50 ocorrências de <a + infinitivo $>$. Poderá, porventura, ser uma influência do $P E$.

Estes dados vêm contrariar aquilo que a maioria da investigação mostrou até ao momento. Contudo, apenas pretendemos constatar dados encontrados nos corpora analisados. 


\section{REFERÊNCIAS BIBLIOGRÁFICAS}

Álvarez, Rosario / Xosé Xove (2002): Gramática da lingua galega. Vigo: Galaxia.

Bartoli, Matteo (1928): Breviario di neolinguistica. Modena: Mucchi Editore (em colaboração com Giulio Bertoni).

Bassols, Mariano (1956/2015): Sintaxis latina. CSIC: Madrid, 1956; Barcelona: Universitat de Barcelona, 2015.

Bertinetto, Marco Pier et al. (2000): "The progressive in Europe", em Östem Dahl (ed.), Tense and Aspect in the languages of Europe. Berlín / New York: Mouton de Gruyten, 559-664.

Brea, Mercedes (1985): "Las preposiciones, del latín a las lenguas románicas", Verba. Anuario Galego de Filoloxía 12, 147-182.

Brocardo, Maria Teresa (2008): "Ainda a analogia (notas em torno da adequação descritiva e valor explicativo do conceito de analogia em linguística histórica)", em Maria Luísa Soares et al. (eds.), Expressões da analogia. Lisboa: Colibri, 185-192.

[CdP] Davies, Mark / Michael Ferreira (2006-): Corpus do Português. National Endowment for the Humanities http://www.corpusdoportugues.org/

[CIPM] Corpus Informatizado do Português Medieval. Faculdade de Ciências Sociais e Humanas da Universidade Nova de Lisboa http://cipm.fcsh. unl.pt/

[CORGA] Centro Ramón Piñeiro para a investigación en humanidades: Corpus de Referencia do Galego Actual (CORGA) [3.0] http://corpus.cirp. gal/corga/

Diez, Friedrich (1836-1844): Grammatik der romanischen Sprachen [versão francesa: Grammaire des langues romaines, 1874-76, Paris].

Fernández Rei, Francisco (1991): Dialectoloxía da lingua galega. Vigo: Xerais.

Fiéis, Alexandra / Maria Lobo (2010): "Aspectos da sintaxe das orações gerundivas no português medieval e no português europeu contemporâneo", em Ana Maria Brito et al. (eds.), Textos selecionados. XXV encontro nacional da Associação Portuguesa de Linguística. Porto: APL, 419-434.

Harto Trujillo, Ma Luisa (1994): "Notas sobre el gerundio y gerundivo", Fortunatae: Revista canaria de filología, cultura y humanidades clásicas 6, 273-292.

Lausberg, Heinrich (19812 [1974']): Linguística Românica. Lisboa: Fundação Calouste Gulbenkian. (Ed. alemã 1963).
Lobo, Maria (2001): "On gerund clauses of Portuguese dialects", em Alexandre Veiga et al. (eds.), El verbo. Entre el léxico y la gramática. Lugo: Ed. Tris Tram, 107-118.

Lobo, Maria (2008): "Variação morfo-sintáctica em dialectos do português europeu: o gerúndio flexionado", Diacrítica 22/1, 25-55.

Maler, Bertil (1973): "L'infinitif gerondival portugais: quelques notes sur la propagation", Stockholm Studies in Modern Philology 4, 250-268.

Mattos e Silva, Rosa Virgínia (1989): Estruturas trecentistas. Elementos para uma gramática do português arcaico. Lisboa: Imprensa Nacional Casa da Moeda.

Mattos e Silva, Rosa Virgínia (2008): O português arcaico. Uma aproximação, vols. I e II. Lisboa: Imprensa Nacional Casa da Moeda.

Meyer-Lübke, Wilhelm (1926): Introducción a la lingüistica románica. Madrid: Gredos.

Mortimer, Liesbeth (2005): "Les périphrases aspectuelles progressives en français et en néerlandais. Présentation et voies de grammaticalisation", em Hava Bat-Zeev Shyld-krot / Nicole Le Querler (eds.), Les périphrases verbales. Amsterdam / Philadelphia: John Benjamins, 83-102.

Mothé, Núbia (2007): Variação e mudança aquém e além mar: gerúndio versus infinitivo gerundivo no Português dos séculos XIX e XX. Universidade Federal do Rio de Janeiro. Dissertação de Mestrado.

Mothé, Núbia (2014): Notícias de Além-mar: Variação e Mudança no uso de infinitivo gerundivo no Português Europeu ao longo do século XX. Universidade Federal do Rio de Janeiro. Tese de Doutoramento.

Muñío Valverde, José Luis (1995): "Pervivencia del participio de presente activo", Romanistisches Jahrbuch 46, 231-250.

[TILG] Santamarina, Antón (coord.): Tesouro Informatizado da lingua galega. Santiago de Compostela: Instituto da Lingua Galega http://www.ti.usc. es/tilg/

[TMILG] Varela Barreiro, Xavier (dir.) (2004-): Tesouro Medieval Informatizado da Lingua Galega. Santiago de Compostela: Instituto da Lingua Galega. http://ilg.usc.es/tmilg/

Väänänen, Veikko (2003 [1971]): Introducción al latín vulgar. Madrid: Gredos.

Webster's New World Dictionary \& Thesaurus (1998). New York: Macmillan Publishers. 
USC 